\title{
A Study of Lexical Ties Used in Medical Science Articles Written by Iranian and English Authors
}

\author{
Masoud Zoghi \\ Dept. of ELT, Ahar Branch, Islamic Azad University, Ahar, Iran \\ E-mail:m-zoghi@iau-ahar.ac.ir \\ Elnaz Reshadi (Corresponding author) \\ Dept. of ELT, Ahar Branch, Islamic Azad University, Ahar, Iran \\ E-mail: e.reshadi@iau-ahar.ac.ir
}

Received: June 17, 2013 Accepted: July 21, 2013 Published: September 11, 2013

doi:10.5296/ijele.v2i1.4261 URL: http://dx.doi.org/10.5296/ijele.v2i1.4261

\begin{abstract}
Establishing a unified text which possesses distinct types of lexical ties is one of the challenging aspects of using a foreign language. This issue even becomes critical when producing the language in a written form is of concern. The present study attempted to compare the frequency of the use of lexical ties in English Medical Sciences (EMSs) articles written by Iranian and native writers. Based on this purpose, the researchers selected two sets of corpora each consisting 10 articles; one written by native authors and the other corpus written by non-native authors. In this research, the researchers examined the use of two types of lexical ties, i.e. reiteration and collocation in abstracts, introduction and discussion and conclusion of native and non-native EMSs articles. After collecting the data from the two sets of corpora, the researchers estimated the frequency of lexical ties. Later on, to compare the use of lexical ties in the two sets of corpora, the researchers used Linear Regression. The results indicated that there was not a statistically significant difference in the use of lexical ties in abstracts, introduction and discussion and conclusion sections of EMSs articles. The research findings have several implications for language instructors and university students.
\end{abstract}

Keywords: Lexical ties, native EMSs articles, non-native EMSs articles 


\section{Introduction}

One of the most challenging aspects of literacy education is to familiarize learners with the act of writing. Actually, writing is a laborious activity since learners need to convey their mental meanings and ideas into language. A related definition has been proposed by Schunk (2004) in which writing was defined as translating ideas into linguistic symbols in print. It is assumed that when learners are entangled in the writing process they need to have access to their underlying knowledge. The knowledge that learners employ while writing is of four types, i.e. topical, audiences, genres, and language (Byrnes, 1996 cited in Schunk, 2004). Writer's understanding of all these knowledge types is necessary since a lack of understanding may make the task of writing even more frustrating and complicated. In other words, writers become perplexed when they need to bind these underlying pieces of knowledge and change them into linguistic symbols.

Irvin (2010) identifies some misconceptions that writers may face will trying to produce written texts. The first misconception is that writers may incorrectly wait for a completely ordered and step-by step framework for writing. In contrast Irvin (2010) assumes a recursive and non-linear format of writing process. The second problem is that most writers try to write only when they have every thing in their mind. Irvin (2010) discards this characteristic of writers and believes that writing should be initiated even with deficiencies in generating a complete text. The third misconception relates to writers idea that they should write well from the very early drafts. The next is that writers are usually disappointed when they are faced with their limited capacity for writing. Another major misconception proposed by Irvin (2010) is that of writers' misbelief about the fact that good grammar is good writing.

Thus, the task of writing is not an easy process; rather writers need to attend fully to the task of writing to produce valuable texts. There are a number of key elements in writing which can enhance writers' ability to manage their writing. Attending to major constituents of written texts is essential in every writing genre. According to Raimes (1983), content, organization, originality, style, fluency, accuracy and using appropriate rhetorical forms of discourse are some of the basic elements of writing which need careful attention.

All writing follows specific conventions. Cookbooks, letters, novels, lists, and dictionaries all depend on a specific kind of language and presentation to be comprehensible and easy to use (Graham, 2004). This is an important issue and it has been of focus since those who are learning a second language need to be able to write in specific ways. Presumably, purposes for writing are different and it is this feature which highlights the specificity of the writing method. In other words, as it is mentioned by Reppen (1995) learners need to be able to write in different ways for different purposes. One way of writing is academic writing.

As mentioned by Hyland (2008), genre, which is one type of knowledge required for writing, represents how writers typically use language to respond to recurring situations. One such situation is concerned with producing texts for academic purposes. Generally, ESL academic writing courses pursue one of the following orientations depending on which element of composing is taken as the basis for organizing the course of instruction (Shih, 1986). The orientations are rhetorical patterns (form), function, process, or content. Whatever the 
orientation is, writers need to have an intuitive and comprehensive understanding of the steps required for writing articles as academic texts. Socolofsky (2004) summarizes a well-accepted format for writing articles, especially engineering and science articles. This format includes eight distinct sections.

$\checkmark$ Abstract: The abstract is a single paragraph that precedes the article and summarizes the content.

$\checkmark$ Introduction: according to Socolofsky (2004), introduction contains at least three paragraphs, the first of which contains broad and detailed information about the problem that the paper addresses. The next two paragraphs are concerned with literature review and outline of the paper.

$\checkmark$ Methods: method is the third section in academic articles which describes all the techniques used to obtain the results.

$\checkmark$ Results: Socolofsky (2004) claims that the results of the article should present the raw data or the results after applying the techniques outlined in the methods section.

$\checkmark$ Discussion: The discussion section is concerned with interpreting the results to reach its major conclusions.

$\checkmark$ Summary and conclusions: As the name implies, this section summarizes and concludes what has already been studied. This sections acts in the same way as abstract except for the fact that summary and conclusions involve more specific and detailed information.

$\checkmark$ Acknowledgement: The acknowledgments give the sources of funding that contributed to the article.

$\checkmark$ References: It is claimed that all reference works cited in the article must appear in a list of references that follow the formatting requirements of the journal in which the article is to be published (Socolofsky, 2004).

Discourse which has attracted the attention of researchers in the realm of communication dates back to the 1960s when researchers became interested in extracting new discipline from linguistics, semiotics, psychology, anthropology and sociology. According to Johnstone (2008), the study of discourse is called discourse analysis and is concerned with the study of the relationship between language and the context in which it is used. Also, McCarthy (1991) believes that those who are involved in the analysis of discourse study language in use. By language in use, McCarthy (1991) refers to written texts of all kinds and spoken data from conversation to highly institutionalized forms of talk. A discourse does not consist of words which are placed together in a random and haphazard fashion. The meaning of discourse is not conveyed by such randomness. Instead, writers need a number of linguistic markers to establish relationships among the words and sentences within the texts. Halliday and Hasan (1985) point out that such semantic relations manifest the texture of the text and provide the situation for establishing a coherent text.

An important contribution to coherence comes from cohesion which refers to a set of 
linguistic resources that every language has as part of the textual metafunction for linking one part of the text to another (Halliday \& Hasan, 1985). Further, Halliday and Hasan (1985) claim that the term cohesive ties implies a relation. In other words, you cannot have a tie without two members and the members cannot appear in a tie unless there is a relation between them. Also Nunan (1993) considers cohesive ties as text-forming devices which enable the writer or speaker to establish relationships across sentence or utterance boundaries, and which help to tie the sentences in a text together. Besides, Eggins (1994) defines cohesion as a term which refers to the way we relate or tie together bits of our discourse.

There are five categories of cohesive ties proposed by Halliday and Hasan (1976). The five categories are reference, substitution, ellipsis, conjunction and lexical cohesion. It needs to be mentioned that Halliday and Hasan's (1976) categorization of cohesive ties which is an umbrella term for lexical ties has been collapsed and later on in 1985 they introduced repetition, synonym, antonym, hyponymy and meronym as the elements of lexical ties. This was not an end in the study and categorization of lexical ties because Halliday (1985, cited in Martin 1992) considered repetition and collocation as distinct categories, and grouped together synonymy, antonym, meronymy and hyponymy under a general heading of synonymy. In the present study, the researchers considered lexical ties under two general headings: reiteration and collocation. Reiteration contains repetition, synonym, superordinate, and general word. The second type of lexical tie is the collocation and is defined by Richards and Schmidt (1992) as the way in which words are used together regularly. Lexical ties are necessary elements for any discourse and they are tools for producing coherent texts.

A number of studies have been conducted focusing on the concept of coherence and the use of cohesive ties since Halliday and Hasan's (1976) introduction of Systemic Functional Linguistics (Hinkel, 2001; Mojica, 2006; \& Petchprasert, 2013). Hinkel (2001) investigated matters of cohesion in L2 academic texts. In her study, Hinkel conducted a comparative analysis of frequency of explicit cohesive devices employed in academic texts of English, Japanese, Korean, Indonesian, and Arabic students. Specifically, she focused on frequency of uses of explicit cohesion devices, such as phrase-level coordinators, sentence transitions, logical semantic conjunctions, demonstrative pronouns, and enumerative and resultative nouns in academic texts of native speakers and nonnative speakers. These quantitative results indicated that even Advanced ESL non-native students rely on a restricted repertoire of features in constructing unified text. The study showed that speakers of Japanese, Korean, Indonesian, and Arabic employ sentence transitions and demonstrative pronouns at significantly higher frequency while compared with native speakers of English. In fact, in L2 texts, Non-native speakers try to construct a unified idea flow within the constraints of a limited syntactic and lexical range of accessible linguistic means. Moreover, this study revealed the frequent use of coordinating conjunctions by Indonesian and Arabic speakers (Hinkel, 2001).

Mojica (2006) Used Halliday and Hasan's (1976) theory on repetition as a sub-type of reiteration in establishing lexical cohesive ties, and Liu's (2000, cited in Mojica, 2006) categorization of this type of cohesion, namely: repetition, synonyms, antonyms, superordinate/hyponyms, related words, and text-structuring words to study the most 
preferred types of lexical cohesion used by ESL learners. She collected the sample from learners' academic papers. Results showed that repetition was the most frequently used type of lexical cohesion by the students. They also frequently employed words like situational synonyms, situational antonyms, lexical items with superordinate/hyponym relationship, and text-structuring words.

Petchprasert (2013) compared the use of cohesive markers used in Thai and English written texts of graduate students who were speakers of Thai. Moreover, he described the use of cohesive markers found in L1 and L2 essays with direct writing and translation. The quantitative analysis of the cohesive markers showed that in the English direct writing essays, writers significantly used more personal reference and demonstratives than those in translation.

Some studies have also been conducted in an Iranian EFL context (Rostami-Abousaeedi, 2010; \& Seddig et al, 2010). Rostami-Abousaeedi (2010) analyzed the use of cohesive ties in the writing samples of 40 Iranian undergraduates of English. In this study, the researcher identified that participants frequently used references in their writings. However, his finding revealed that referential ties were not effective in giving coherence to the text. Also, his analysis showed that substitution and ellipsis were the least frequently used cohesive ties. Besides, Seddig et al (2010) examined lexical cohesion in English and Persian abstracts. In their study, they compared and contrasted lexical cohesion in one hundred English and Persian abstracts of Iranian medical students' theses to scrutinize the textualiztion in the two languages. The results showed that the two groups of abstracts were not significantly different. Also, the results showed that there was a great tendency in using repetition in both languages. However, regarding the density of the texts, the analysis indicates that Persian abstracts are denser than their corresponding English ones.

English Medical Sciences (EMSs) articles produced by the experts in the field are the result of some attempts on the part of researchers to express their new findings. Academic research writers need to be active and wise to employ unifying features to establish grammatical and lexical cohesion in their texts. One of the necessary elements in producing EMSs articles is the use of lexical ties which have the capability of relating the parts of a text semantically. This research is of significance to the domain of written skill since it gives attention to unifying elements that exist in every coherent text. The concept of cohesive ties and respectively lexical ties is not a new term in the field of linguistics. The concept and its use by second language learners have been of foci to many researchers and have been studied in recent years (Halliday \& Hasan, 1976; \& Halliday \& Hasan, 1985). However, English academic writing tasks which are written by native versus non-native authors need to be studied in more detail. The reason lies on the fact that writers with different nationalities might prefer distinct amount of lexical ties while writing articles. For this purpose, the following research question and hypothesis was posed:

- Does the use of lexical ties vary in English Medial Sciences articles written by Iranian versus native authors? 
- The use of lexical ties varies in English Medial Sciences articles written by Iranian versus native authors.

\section{Method}

Writers all around the world usually write with an intention to inform their audience of a specific fact or give extra information about an issue. In this case, they put an effort to keep themselves away from falsifying the reality. The writers need not to distort their audience's understanding by providing jumble utterances; rather, they need to keep in mind that the audience must be faced with a text which has already been organized by the writer. One such organizing factor which gives unity to the text is lexical ties.

\subsection{The Corpus of the Study}

The main objective of the present study was to study the use of lexical ties in medical science article. In fact, researchers studied and compared this unifying feature in the academic articles written by native and non-native English speakers. The present study required the use of a monolingual corpus of EMSs articles, containing approximately 121804 words. The two sets of articles were drawn from two English journals to investigate the use of lexical ties by native and non-native English authors. The first journal was Iranian Journal of Medical Sciences. Iranian Journal of Medical Sciences (IJMS) is an international quarterly biomedical publication, which is sponsored by Shiraz University of Medical Sciences and has been published since 1970. The second set of corpora is taken from International Journal of Medical Science. This is a journal which publishes papers of significance in areas of basic medical sciences and clinical research related to the studies of human diseases. An important point about this journal is that its official impact factor is 2.244 according to the latest Journal Citation Report from Thomson Reuters.

It is important to note that the data for the present study consisted of 20 EMSs articles. Actually, 10 articles were part of non native EMSs articles written by Iranian authors and they were consisted of approximately 56823 words. In contrast, the other 10 articles were related to EMSs articles written by native English authors and were approximately 64981 words. This study can be classified as a quantitative and a qualitative research in which the researcher used numbers to estimate the number of lexical ties in the two corpus and to qualitatively compare the use of lexical ties in native and non-native EMSS articles.

\subsection{The Construction of the Corpus}

The published academic articles of most authors, either native or non-native show a consistency in following specific orders. In fact, most published articles attach to a fixed format and follow the steps and sessions required by the editors of the journals. In this study, the researcher opted for specific sections of the selected EMSs articles to investigate the use of lexical ties by the authors. Thus, to conduct data collection procedure, the researchers attended to those articles which had abstract, introduction, discussion and conclusion.

Abstract: The abstracts of non-native English articles consisted of approximately 2034 words. A major characteristic of the abstracts in this group was their classification into four distinct 
parts. In fact, those who wanted to submit an article to Iranian Journal of Medical Sciences were required to divide their abstract into four distinct parts: backgrounds, methods, results and conclusion. Moreover, the abstracts of native English medical articles consisted of about 2118 words.

Introduction: Specifying the introduction section of the 20 articles was also of great importance to the researchers since the corpus of study required the analysis of lexical ties in introduction section of native and non-native EMSS articles. The introduction parts of the articles of the present corpus consisted of a total of 17120 words. That is, the introductions of non-native medical corpora consisted of 8518 words and the introductions of native medical corpora consisted of approximately 8602 words.

Discussion and Conclusion: In this study, the researchers considered discussion and conclusion sections as a single section and analyzed them together. Approximately 9919 words consisted the discussion and conclusion sections of non-native articles. In contrast, native EMSs articles had about 11091 words.

\subsection{Procedures for Corpus Analysis}

The researches started this study by attending to two key features. The first feature was that half of the articles must be written by native English speakers and the other half must be authored by non-native English speakers. The second major characteristic was that the selected EMSs articles should have been consisted of three major parts, i.e. abstract, introduction, discussion and conclusion. For this purpose 10 native and 10 non-native EMSs articles have been selected which consisted of approximately of 21811 and 20471 words, respectively.

The next step which came after determining the journals and articles was to estimate the frequency of occurrence of the lexical ties in the EMSs articles written by native and non-native English authors. The researchers used the common lexical ties categorization of Firth (1957 \& 1968 cited in Martin, 1992), Halliday and Hasan (1976), Halliday (1985, cited in Martin 1992), and Martin (1992) as a criterion for identifying the lexical ties.

After determining the distribution of the lexical ties in three sections of the two corpora, the researchers compared the data in the two groups of corpus. It is important to note that the researchers used Linear Regression to compare the mean of the use of lexical ties in the two sets of corpus. Using Linear Regression, the author compared the use of lexical ties in three sections of the articles in the two groups. In addition, the researchers took advantage of this statistical test to estimate the degree of significance between the two groups in terms of three sections of the articles.

\section{Results}

Determining the use of lexical ties in EMSs articles written by native and non-native English speakers was the major challenge of this section. Obviously, the researcher tried to estimate the frequency of different categories of lexical ties manually. In this study, the researcher analyzed the use of reiteration and collocation as two general types of lexical ties in native 
and non-native EMSs articles.

\subsection{Reiteration in Native and Non-native Articles}

As discussed earlier, reiteration can be classified as repetition, synonym, super ordinate and general word. Table 1 tabulates the frequency of the use of reiteration in three distinct parts of the EMSs articles written by native English authors. While the most frequent reiteration in abstract and discussion and conclusion is repetition, synonym is the most frequent reiteration in introduction section.

Table 1. Frequency of distinct reiterations in native EMSs articles

\begin{tabular}{|c|c|c|c|c|c|c|c|}
\hline \multirow{2}{*}{ No } & \multirow{2}{*}{$\begin{array}{l}\text { Reiterations as } \\
\text { lexical ties }\end{array}$} & \multicolumn{2}{|c|}{ Abstract } & \multicolumn{2}{|c|}{$\begin{array}{l}\text { Introductio } \\
\mathrm{n}\end{array}$} & \multicolumn{2}{|c|}{$\begin{array}{l}\text { Discussion } \\
\text { and } \\
\text { Conclusion }\end{array}$} \\
\hline & & $\mathrm{F}$ & $\begin{array}{l}\text { F per } \\
1,000 \\
\text { words }\end{array}$ & $\mathrm{F}$ & $\begin{array}{l}\text { F per } \\
1,000 \\
\text { words }\end{array}$ & $\mathrm{F}$ & $\begin{array}{l}\text { F per } \\
1,000 \\
\text { words }\end{array}$ \\
\hline 1 & Repetition & 17 & 8.0 & $\begin{array}{l}3 \\
5\end{array}$ & 4.1 & $\begin{array}{l}10 \\
2\end{array}$ & 9.2 \\
\hline 2 & Synonym & 6 & 2.8 & $\begin{array}{l}3 \\
7\end{array}$ & 4.3 & 41 & 3.7 \\
\hline 3 & Super ordinate & 8 & 3.8 & $\begin{array}{l}1 \\
6\end{array}$ & 1.9 & 34 & 3.1 \\
\hline 4 & General word & 2 & .94 & 8 & 0.9 & 30 & 2.7 \\
\hline & $\begin{array}{l}\text { Total } \\
\text { reiterations }\end{array}$ & 33 & 15.6 & $\begin{array}{l}9 \\
6\end{array}$ & 11.2 & $\begin{array}{l}20 \\
7\end{array}$ & 18.7 \\
\hline & Total word & 2,11 & & & & 11,0 & \\
\hline
\end{tabular}

Also, reiteration as a type of lexical ties studied in non-native EMSs articles. Table 2 presents the findings of manual analysis of repetition, synonym, super ordinate and general word in three sections of non-native EMSs articles. in non-native EMSS corpus, the most frequently used reiteration is repetition. 
Table 2. Frequency of distinct reiterations in non-native EMSs articles

\begin{tabular}{|l|l|l|l|l|l|l|l|}
\hline \multirow{2}{*}{ No } & \multirow{2}{*}{$\begin{array}{l}\text { Reiterations as } \\
\text { lexical ties }\end{array}$} & \multicolumn{2}{|l|}{ Abstract } & \multicolumn{2}{l|}{$\begin{array}{l}\text { Introductio } \\
\text { n }\end{array}$} & \multicolumn{2}{l|}{$\begin{array}{l}\text { Discussion } \\
\text { and } \\
\text { Conclusion }\end{array}$} \\
\cline { 3 - 8 } & & F & $\begin{array}{l}\text { F per } \\
1,000 \\
\text { words }\end{array}$ & F & $\begin{array}{l}\text { F per } \\
1,000 \\
\text { words }\end{array}$ & F & $\begin{array}{l}\text { F per } \\
1,000 \\
\text { words }\end{array}$ \\
\hline 1 & Repetition & 11 & 5.4 & $\begin{array}{l}2 \\
4\end{array}$ & 2.8 & 74 & 7.5 \\
\hline 2 & Synonym & 3 & 1.5 & $\begin{array}{l}2 \\
9\end{array}$ & 3.4 & 23 & 2.3 \\
\hline 3 & Super ordinate & 0 & 0 & 6 & 0.7 & 16 & 1.6 \\
\hline 4 & General word & 2 & 1.0 & $\begin{array}{l}1 \\
6\end{array}$ & 1.9 & 51 & 5.1 \\
\hline & $\begin{array}{l}\text { Total } \\
\text { reiterations }\end{array}$ & 16 & 7.9 & $\begin{array}{l}7 \\
5\end{array}$ & 2,034 & 8,518 & $\begin{array}{l}16 \\
4\end{array}$ \\
\hline
\end{tabular}

\subsection{Collocation in Native and Non-native Articles}

Collocation was the second type of lexical ties to be studied in this paper. The researchers analyzed collocation in both native and non-native EMSs articles. Table 3 presents the use of collocations in native EMSs articles' abstracts, introductions, discussions and conclusions. The results of this table show that abstract, introduction, discussion and conclusion sections contain $6.1,7.9$ and 9.1 collocations, respectively.

Table 3. Frequency of collocations in native EMSs articles

\begin{tabular}{|l|l|l|l|l|l|l|l|}
\hline \multirow{2}{*}{ No } & \multirow{2}{*}{$\begin{array}{l}\text { Collocations as } \\
\text { lexical ties }\end{array}$} & \multicolumn{2}{|l|}{ Abstract } & \multicolumn{2}{l|}{$\begin{array}{l}\text { Introductio } \\
\mathrm{n}\end{array}$} & \multicolumn{2}{l|}{$\begin{array}{l}\text { Discussion } \\
\text { and } \\
\text { conclusion }\end{array}$} \\
\cline { 3 - 8 } & F & $\begin{array}{l}\text { F per } \\
1,000 \\
\text { words }\end{array}$ & F & $\begin{array}{l}\text { F per } \\
1,000 \\
\text { words }\end{array}$ & F & $\begin{array}{l}\text { F per } \\
1,000 \\
\text { words }\end{array}$ \\
\hline 1 & Collocations & 13 & 6.1 & $\begin{array}{l}6 \\
8\end{array}$ & 7.9 & 82 & 9.1 \\
\hline & Total word & 2,118 & 8,602 & \multicolumn{2}{l|}{11,091} \\
\hline
\end{tabular}


Besides, the researcher investigated the use of collocations in the abstract, introduction, discussion and conclusion of non-native EMSs articles. As it is evident in Table 4, the abstract section of non-native EMSs articles contains 4.4 collocations per 1000 words. Besides, introduction and discussion and conclusion contain 5.7 and 8.0 collocations per 1000 words.

Table 4. Frequency of collocations in non-native EMSs articles

\begin{tabular}{|c|c|c|c|c|c|c|c|}
\hline \multirow{2}{*}{ No } & \multirow{2}{*}{$\begin{array}{l}\text { Collocations as } \\
\text { lexical ties }\end{array}$} & \multicolumn{2}{|c|}{ Abstract } & \multicolumn{2}{|c|}{$\begin{array}{l}\text { Introductio } \\
\mathrm{n}\end{array}$} & \multicolumn{2}{|c|}{$\begin{array}{l}\text { Discussion } \\
\text { and } \\
\text { conclusion }\end{array}$} \\
\hline & & $\mathrm{F}$ & $\begin{array}{l}\text { F per } \\
1,000 \\
\text { words }\end{array}$ & $\mathrm{F}$ & $\begin{array}{l}\text { F per } \\
1,000 \\
\text { words }\end{array}$ & $\mathrm{F}$ & $\begin{array}{l}\text { F per } \\
1,000 \\
\text { words }\end{array}$ \\
\hline \multirow[t]{2}{*}{1} & Collocations & 9 & 4.4 & $\begin{array}{l}4 \\
9\end{array}$ & 5.7 & 79 & 8.0 \\
\hline & Total word & \multicolumn{2}{|c|}{2,034} & \multicolumn{2}{|c|}{8,518} & \multicolumn{2}{|c|}{9,919} \\
\hline
\end{tabular}

\subsection{Comparing Lexical ties in Native and Non-native Articles}

In order to test the existence of a significant difference between native and non-native EMSs articles' abstract, introduction, discussion and conclusion in terms of the use of lexical ties, the researchers used Linear Regression. The results of the test are presented in the following tables. As it is represented in Table 5, the $\mathrm{p}$ value for the present study is $.451>.005$. It indicates that authors' nationality has no significant relationship with the use of two types of lexical ties in abstracts of EMSs articles. The results are $F(1,20)=0.862, p=0.45, \beta=-0.549$.

Table 5. Relationship between native/non-native EMSs articles and of the use of lexical ties in abstracts

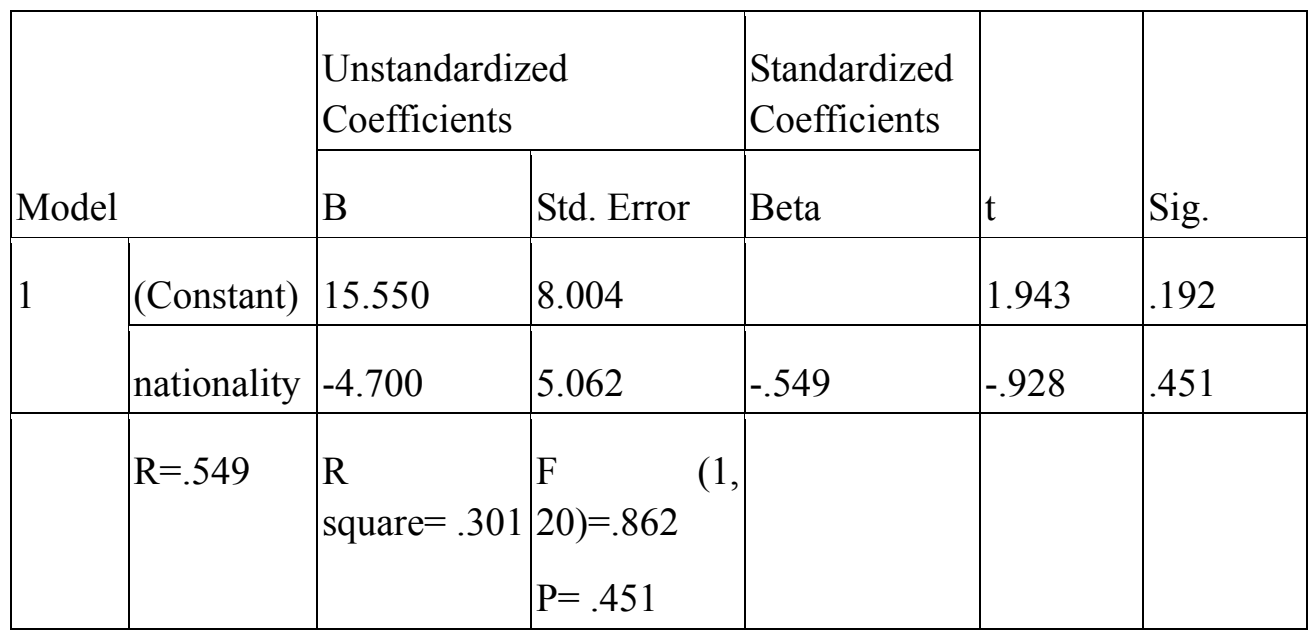


Besides, Table 6 presents the result of the Linear Regression for the relationship between nationality of the authors and the use of lexical ties in introduction section. The findings of this statistical analysis shows that the significance of the is not significant $(\mathrm{p}=.417>.05)$. The results of this study are $\mathrm{F}(1,20)=1.03, \mathrm{p}=.417, \beta=-0.583$.

Table 6. Relationship between native/ non-native EMSs articles and of the use of lexical ties in introduction

\begin{tabular}{|c|c|c|c|c|c|c|}
\hline \multirow{2}{*}{\multicolumn{2}{|c|}{ Model }} & \multicolumn{2}{|c|}{$\begin{array}{l}\text { Unstandardized } \\
\text { Coefficients }\end{array}$} & \multirow{2}{*}{\begin{tabular}{|l}
$\begin{array}{l}\text { Standardized } \\
\text { Coefficients }\end{array}$ \\
Beta
\end{tabular}} & \multirow[b]{2}{*}{$\mathrm{t}$} & \multirow[b]{2}{*}{ Sig. } \\
\hline & & B & Std. Error & & & \\
\hline \multirow[t]{3}{*}{1} & (Constant) & 11.850 & 3.579 & & 3.311 & .080 \\
\hline & nationality & -2.300 & 2.264 & -.583 & -1.016 & .417 \\
\hline & $\mathrm{R}=.583$ & $\begin{array}{l}\mathrm{R} \\
\text { square }=.340\end{array}$ & $\left\{\begin{array}{l}\mathrm{F}(1, \quad 20)= \\
1.03 \\
\mathrm{P}=.417\end{array}\right.$ & & & \\
\hline
\end{tabular}

Finally, the researchers used Linear Regression to estimate the relationship between nationality of authors and their use of lexical ties in discussion and conclusion sections of EMSs articles. The result is $\mathrm{F}(1,20)=.150, \mathrm{p}=.736, \beta=-0.264$ (see Table 7 ). In fact, the results of this table shows that the difference between native and non-native EMSs is not significant and the two sets of corpora are not statistically different in the use of lexical ties.

Table 7. Relationship between native/non-native EMSs articles and of the use of lexical ties in discussion and conclusion

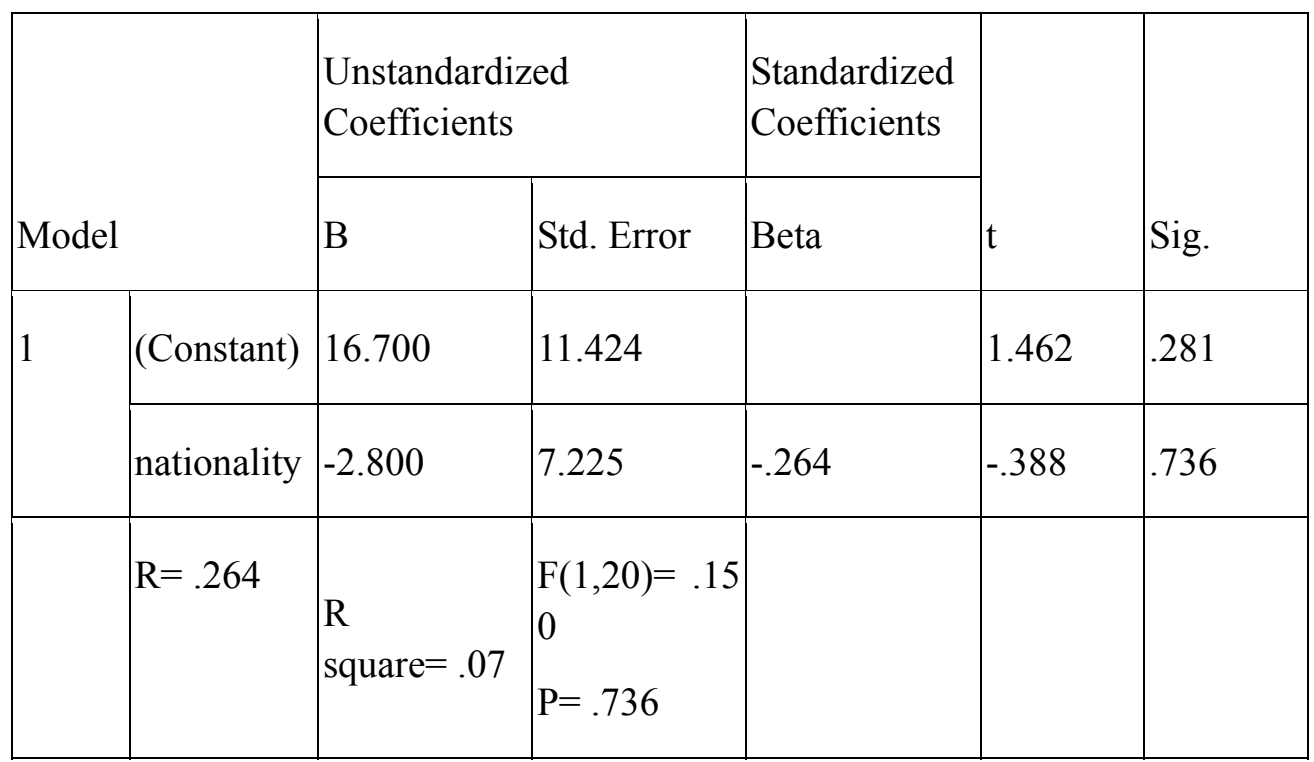




\section{Discussion}

The main purpose of the present study was based on EMSs articles written by the experts in the field to express their new findings. The researcher believes that academic contexts require the writers to attend to linguistic as well as meaning features in the writing texts. The reason is to make such texts more comprehensible and interpretable to the intended audience. One such feature is the use of lexical ties to convey meaning to the readers in a coherent way. The purpose of the present study was to compare the use of lexical ties in EMSs articles written by native English authors and non-native English authors (Iranian authors).

For this purpose the researcher questioned and compared the use of lexical ties in native and non-native EMSs articles. Based on the research question, the researcher analyzed three sections (abstract, introduction, and discussion and conclusion) of the two corpora. In fact, the major features to be analyzed as lexical ties were reiterations and collocations.

In the case of abstracts, the researcher reported that the two corpora were akin with regard to the use of lexical ties. The results were admitted when a Linear Regression has been conducted and a significance of 0.451 has been reported. As this value shows, the two groups of writers face no differences in the use of lexical ties in abstract of EMSs articles.

Moreover, the researcher analyzed the frequency of the use of lexical ties in the introduction of EMSs articles. Similarly, the two groups of writers shared commonalities in the use of lexical ties in this section. In other words, analysis of Linear Regression revealed that there was no significant difference in the use of lexical ties in the English texts produced by Iranian and native writers $(\mathrm{p}=.417>.05)$.

The same results have been reported for discussion and conclusion sections. Owing to the fact that the Linear Regression results revealed a significance of .736, the researchers assumed that the frequency of the use of lexical ties in both groups of corpora were same and there was non significance difference in the use of lexical ties in discussion and conclusion.

This study has pedagogical implications both for teachers and university students. It is the availability of such implications which motivated the progress of this paper. Although, the differences were not significant, the mean score of lexical ties were lower in non-native group while compared with native English speakers' articles. This highlights the need for non-native English users to attend to such cohesive markers as lexical ties to convey their meanings in a unified and coherent manner. This also requires language teachers' attention to the instruction of lexical ties as important features of producing coherent texts.

This study is not general enough to answer all questions related to the use of lexical ties in all types of academic articles. Further research is needed to concentrate on distinct types of academic arils and the use of lexical ties.

\section{References}

Eggins, S. (1994). An Introduction to Systemic Functional. London: Printer publishers Ltd. Graham, A. (2004). A Guide to Reading and Analyzing Academic Articles. Retrieved from 
http://www.mikehart-papers.co.uk/tutorials/read_an.doc

Halliday, M. A. K., \& Hasan, R. (1976). System and Function in Language. London: Oxford University Press.

Halliday, M. A. K., \& Hasan, R. (1985). Language, Context, and Text: Aspects of Language in a Social-Semiotic Perspective. Oxford University Press: Oxford.

Hinkel, E. (2001). Matters of cohesion in L2 academic texts. Applied Language Learning, $12(2), 111-132$.

Hyland, K. (2008). Genre and academic writing in the disciplines. Lang. Teach. 41(4), 543-562. http://dx.doi.org/10.1017/S0261444808005235

Irvin, L. L. (2010). What is academic writing. Retrieved from http://wac.colostate.edu/books/writingspaces1/irvin--what-is-academic-writing.pdf

Johnstone, B. (2008). Discourse Analysis. Oxford: Blackwell publishers Ltd.

Martin, J. R. (1992). English Text: System and Structure. John Benjamin's Publishing Co.: The Netherlands.

McCarthy, M. (1991). Discourse Analysis for Language Teachers. Cambridge University Press: Cambridge.

Mojica, L. A. (2006). Reiterations in ESL learners' academic papers: do they contribute to lexical cohesiveness? The Asia-Pacific Education Research. 15(1), 105-125.

Nunan, D. (1993). Introducing Discourse Analysis. Penguin Group: England.

Petchprasert, A. (2013). A study of cohesive markers used in L1 and L2 essay writing: translation versus direct composition. The Southeast Asian Journal of English Language Studies, 19(1), 19-33.

Raimes. (1983). Tradition and revolution in ESL teaching. TESOL Quarterly 17, 535-552.

Reppen. R. (1995). A genre-based approach to content writing instruction. TESOL Journal, 4, 32-35.

Richards, J.C. \& Schmidt, R. (1992). Longman Dictionary of Language Teaching and Applied Linguistics. London: Longman.

Rostami-Abousaeedi, A. A. (2010). Use of cohesive ties in English as a foreign language students' writing. Iranian Journal of Applied Language Studies, 2(1), 137-156.

Schunk, D. H. (2004). Learning theories: an educational perspective. New Jersey: Pearson.

Seddig, F., Shokrpour, N., \& Kafipour, R. (2010). Lexical cohesion in English an Persian abstracts. Iranian Journal of Applied Language Studies 2(1), 157-168.

Socolofsky, S. A. (2004). How to write a research journal article in engineering and science. Retrieved from https://ceprofs.civil.tamu.edu/ssocolofsky/downloads/paper_how-to.pdf 


\section{Macrothink}

International Journal of English Language Education

ISSN 2325-0887 2013, Vol. 2, No. 1

Shih, M. (1986). Content-Based Approaches to Teaching Academic Writing. TESOL Quarterly, 20(4). http://dx.doi.org/10.2307/3586515

\section{Copyright Disclaimer}

Copyright reserved by the author(s).

This article is an open-access article distributed under the terms and conditions of the Creative Commons Attribution license (http://creativecommons.org/licenses/by/3.0/). 